\title{
Juvenile-only clusters and behaviour of the Early Cretaceous dinosaur Psittacosaurus
}

Qi Zhao, Michael J. Benton, Xing Xu, and P. Martin Sander

Acta Palaeontologica Polonica 59 (4), 2014: 827-833 doi: http://dx.doi.org/10.4202/app.2012.0128

It has hitherto been hard to prove that any association of juvenile dinosaurs represents original behaviour rather than sedimentary accumulation, and it has been hard also to determine the ages of such juveniles. A previously described specimen, which consists of an "adult" Psittacosaurus with 34 fully articulated juveniles, turns out to be a composite: the "adult" skull probably has been added, and in any case it is below breeding age. Other juvenile-only clusters have been reported, but the best examples that likely reflect behaviour rather than sedimentary accumulation are specimens from the Early Cretaceous Lujiatun beds in NE China, which were entombed beneath pyroclastic flow deposits. A remarkable juvenile-only cluster of Psittacosaurus shows clear evidence of different ages (five 2-year olds and one 3-year old) based on bone histological analysis. These juveniles may have associated together as a close-knit, mixed-age herd either for protection, to enhance their foraging, or as putative helpers at the parental nest.

Key words: Dinosauria, ceratopsian, juvenile-only, mixed-age, bone histology, Cretaceous.

Qi Zhao [q.zhao@ bristol.ac.uk], School of Earth Sciences, University of Bristol, Bristol BS8 1RJ, UK and Key Laboratory of Evolutionary Systematics of Vertebrates, Institute of Vertebrate Paleontology and Paleoanthropology, Chinese Academy of Sciences, PO Box 643, Beijing 100044, China; Michael J. Benton [Mike.Benton@ bristol.ac.uk], School of Earth Sciences, University of Bristol, Bristol BS8 1RJ, UK; Xing Xu [xuxing@ivpp.ac.cn ], Key Laboratory of Evolutionary Systematics of Vertebrates, Institute of Vertebrate Paleontology and Paleoanthropology, Chinese Academy of Sciences, PO Box 643, Beijing 100044, China; P. Martin Sander [martin.sander@uni-bonn.de], Division of Paleontology, Steinmann Institute, Rheinische Friedrich-Wilhelms-Universität Bonn, Nussallee 8, D-53115 Bonn, Germany. 
This is an open-access article distributed under the terms of the Creative Commons

Attribution License (for details please see creativecommons.org), which permits unrestricted use, distribution, and reproduction in any medium, provided the original author and source are credited.

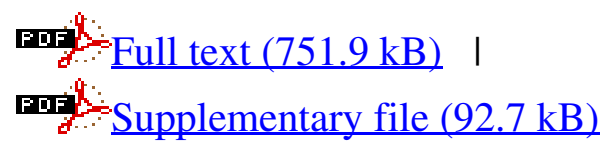

